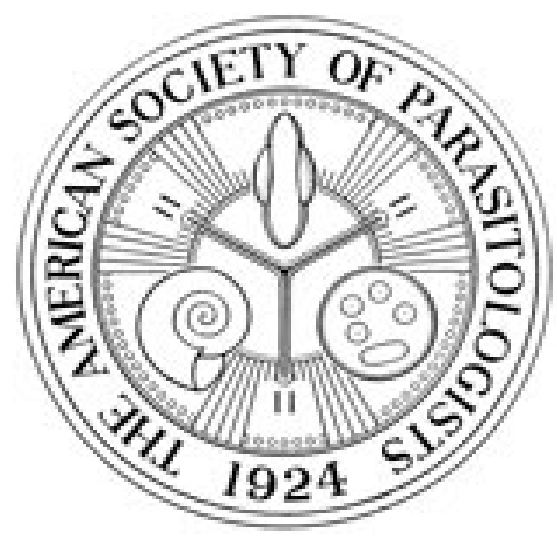

Sarcocystis neurona n. sp. (Protozoa: Apicomplexa), the Etiologic Agent of Equine Protozoal Myeloencephalitis

Author(s): J. P. Dubey, S. W. Davis, C. A. Speer, D. D. Bowman, A. de Lahunta, D. E.

Granstrom, M. J. Topper, A. N. Hamir, J. F. Cummings and M. M. Suter

Source: The Journal of Parasitology, Vol. 77, No. 2 (Apr., 1991), pp. 212-218

Published by: The American Society of Parasitologists

Stable URL: http://www.jstor.org/stable/3283084

Accessed: 25/09/2013 03:34

Your use of the JSTOR archive indicates your acceptance of the Terms \& Conditions of Use, available at http://www.jstor.org/page/info/about/policies/terms.jsp

JSTOR is a not-for-profit service that helps scholars, researchers, and students discover, use, and build upon a wide range of content in a trusted digital archive. We use information technology and tools to increase productivity and facilitate new forms of scholarship. For more information about JSTOR, please contact support@ jstor.org.

The American Society of Parasitologists is collaborating with JSTOR to digitize, preserve and extend access to The Journal of Parasitology. 


\title{
SARCOCYSTIS NEURONA N. SP. (PROTOZOA: APICOMPLEXA), THE ETIOLOGIC AGENT OF EQUINE PROTOZOAL MYELOENCEPHALITIS
}

\author{
J. P. Dubey, S. W. Davis, C. A. Speer ${ }^{\star}$, D. D. Bowmant, \\ A. de Lahunta†, D. E. Granstrom‡, M. J. Topper§, \\ A. N. Hamir\|, J. F. Cummings $\dagger$, and M. M. Suter $\dagger$ \\ Zoonotic Diseases Laboratory, Livestock and Poultry Sciences Institute, \\ Agricultural Research Service, U.S. Department of Agriculture, Beltsville, Maryland 20705
}

\begin{abstract}
Sarcocystis neurona $\mathrm{n}$. sp. is proposed for the apicomplexan taxon associated with myeloencephalitis in horses. Only asexual stages of this parasite presently are known, and they are found within neural cells and leukocytes of the brain and spinal cord. The parasite is located in the host cell cytoplasm, does not have a parasitophorous vacuole, and divides by endopolygeny. Schizonts are 5-35 $\mu \mathrm{m} \times 5-20 \mu \mathrm{m}$ and contain 4-40 merozoites arranged in a rosette around a prominent residual body. Merozoites are approximately $4 \times 1 \mu \mathrm{m}$, have a central nucleus, and lack rhoptries. Schizonts and merozoites react with Sarcocystis cruzi antiserum but not with Caryospora bigenetica, Toxoplasma gondii, Hammondia hammondi, or Neospora caninum antisera in an immunohistochemical test.
\end{abstract}

A fatal protozoan encephalomyelitis (EPM) infection was reported originally from horses from Illinois (Cusick et al., 1974), Ohio (Dubey et al., 1974), and Pennsylvania (Beech, 1974; Beech and Dodd, 1974). Since then, this disease has been reported from horses throughout North America (Brown and Patton, 1977; Mayhew and de Lahunta, 1978; Mayhew et al., 1978; Clark et al., 1981; Dorr et al., 1984; Dubey and Miller, 1986; Mayhew and Greiner, 1986; Fayer and Dubey, 1987; Madigan and Higgins, 1987; Brewer and Mayhew, 1988; Fayer et al., 1990). Although the parasite initially was thought (Cusick et al., 1974) to be Toxoplasma gondii, structural studies (Dubey, 1974; Dubey et al., 1974) indicated that the parasite was not $T$. gondii but possibly (Simpson and Mayhew, 1980) a species of Sarcocystis. Sera from a large percentage of horses with EPM reacted with Sarcocystis cruzi antigen in an indirect hemagglutination test, suggesting that the EPM organism may be related to Sarcocystis (Mayhew et al., 1978). Further life

Received 7 August 1990; revised 15 October 1990; accepted 25 October 1990.

* Veterinary Molecular Biology, Montana State University, Bozeman, Montana 59717.

† New York State College of Veterinary Medicine, Cornell University, Ithaca, New York 14853-6401.

$\ddagger$ Department of Veterinary Science, University of Kentucky, Lexington, Kentucky 40546-0099.

$\S$ U.S. Army Medical Research Institute of Infectious Diseases, Fort Detrick, Maryland 21702.

\| New Bolton Center, School of Veterinary Medicine, University of Pennsylvania, Kennett Square, Pennsylvania 19348 . cycle and transmission studies have not been successful because the parasite rarely was found in tissues probably as a result of sulfadiazine chemotherapy (Boy et al., 1990; Fayer et al., 1990). Recently, an EPM-like organism was cultured in cells from a naturally infected horse. In the present report we describe the structure of the organism from naturally infected horses, compare it with the cultured organism, and propose a name for it.

\section{MATERIALS AND METHODS}

Specimens of brains and spinal cords of numerous naturally infected horses from published reports including those of Beech and Dodd (1974), Cusick et al. (1974), Dubey et al. (1974), and Madigan and Higgins (1987) as well as unreported cases were reexamined for this report. Tissues usually had been fixed in $10 \%$ buffered neutral formalin. Paraffin-embedded sections of tissues were cut $(2-6 \mu \mathrm{m})$ and stained with hematoxylin and eosin (H\&E), periodic acid Schiff (PAS) hematoxylin, and Wilder's ammoniacal silver. Formalin-fixed tissues or deparaffinized tissue sections were processed for transmission electron microscopy (TEM) by standard techniques.

An EPM-like organism was cultured from a naturally infected horse killed at the New York State College of Veterinary Medicine, Cornell University, Ithaca, New York. Specimens of spinal cord with discolored malacic lesions were teased and then ground with mortar and pestle in $5 \mathrm{ml}$ of chilled Hanks' balanced salt solution (HBSS). The resulting suspension then was washed once in $50 \mathrm{ml}$ HBSS by centrifugation at 800 $g$ for $10 \mathrm{~min}$. The pellet was resuspended in $5 \mathrm{ml}$ sterile $0.9 \% \mathrm{NaCl}$ solution and $0.5 \mathrm{ml}$ of the suspension was pipetted into a $25-\mathrm{cm}^{2}$ culture flask containing bovine monocytes (BM) (Speer et al., 1985). Growth medium was RPMI- 1640 plus 3\% fetal bovine serum, $2 \mathrm{mM}$ L-glutamine, $10 \mathrm{mM}$ HEPES, $1 \mathrm{mM}$ sodium pyruvate, 
$5 \times 10^{-2} \mathrm{mM} 2$-mercaptoethanol, and $100 \mu \mathrm{g} / \mathrm{ml}$ gentamicin. Cultures were incubated at $37 \mathrm{C}$ in a $5 \% \mathrm{CO}_{2}$ incubator for up to $1 \mathrm{hr}$ before pipetting off the medium, washing flasks with HBSS, and adding fresh medium. Twenty days following the primary inoculation, a flask of BM cells containing several recognizable schizonts as well as extracellular zoites was scraped with a cell scraper. A portion of this cell suspension was washed in HBSS, followed by the addition of icecold $2.5 \%$ glutaraldehyde in $0.1 \mathrm{M}$ sodium cacodylate buffer $\mathrm{pH} 7.4$ to the pellet. The pellet then was processed for TEM by standard techniques.

For immunohistochemical staining, paraffin-embedded sections $(5-6 \mu \mathrm{m})$ from naturally infected horses were reacted with antisera raised against $T$. gondii, Caryospora bigenetica, Neospora caninum, Hammondia hammondi, and $S$. cruzi in an avidin-biotinimmunoperoxidase complex test as described by Lindsay and Dubey (1989). The sera were prepared in rabbits and appropriate controls were included in each test. Methods used to generate sera in rabbits against $T$. gondii, $N$. canicum, H. hammondi, and C. bigenetica and the methods used to examine the specificity of these reagents have been described (Lindsay and Dubey, 1989; Dubey, Black et al., 1990). The anti-S. cruzi serum used was prepared by Granstrom et al. (1990). For Sarcocystis control slides, tissues experimentally infected with $S$. cruzi (Dubey, 1982), Sarcocystis capracanis (Dubey et al., 1984), and Sarcocystis tenella (Dubey et al., 1982) containing sarcocysts and schizonts were used.

\section{DESCRIPTION}

\section{Sarcocystis neurona n. sp.}

(Figs. 1-10)

Diagnosis: Only asexual stages known. Schizonts and merozoites PAS-negative and located in cytoplasm of neural cells, leukocytes, and giant cells in gray and white matter of brain and spinal cord of horses. Schizonts divide by endopolygeny. By light microscopy earliest uninucleated schizonts $(4-7 \mu \mathrm{m} \times 4-5 \mu \mathrm{m})$ contain a large nucleus with a nucleolus (Figs. 1,2), nucleus in larger schizonts lobulated (Figs. 2, 3), in some schizonts nuclear division not seen until schizont $15 \mu \mathrm{m}$ long. In 5-6- $\mu \mathrm{m}$ H\&E-stained sections structure of dividing nucleus often not clear and appears as a granulated mass, nuclear structure visible optimally in silverstained sections (Fig. 3). Merozoites bud from periphery of multilobed nucleus, occasionally arranged in a rosette around a residual body (Figs. 2,4 ). Schizonts 5-35 $\mu \mathrm{m} \times 5-20 \mu \mathrm{m}$ and contain 4-40 merozoites. Mature merozoites $2-4 \times 1-2 \mu \mathrm{m}$ with centrally located nuclei (Fig. 5).

Ultrastructurally, parasites from tissues of horses and cell culture located free in the host cell cytoplasm without a parasitophorous vacuole (Figs. 6-10). Merozoites develop exclusively by endopolygeny, 2 merozoite anlagen appear in close proximity to a spindle apparatus associated with each lobe of a highly irregularly shaped nucleus (Fig. 7). Each merozoite anlagen elongates by posterior extension of its inner membrane complex and subpellicular microtubules and eventually incorporates within it a part of the schizont nucleus and cytoplasm (Fig. 7). The pellicular membrane folds in around developing merozoites until they appear to bud at the schizont surface (Fig. 8). After merozoites form completely, a prominent and relatively large residual body remains (Fig. 9). Merozoites $4.1 \times 1.2 \mu \mathrm{m}(3.6-5.8 \times$ 1-2 $\mu \mathrm{m} ; \mathrm{n}=8$ ), lack rhoptries but contain micronemes and usually a large, mostly empty vacuole (approximately $0.75 \mu \mathrm{m}$ in diameter) between the nucleus and anterior tip (Fig. 10). Tissue cysts and sexual stages unknown.

\section{Taxonomic summary}

Type host: Equus caballus (horse).

Distribution: North America.

Specimens deposited: Syntypes from horse no. 1 of Dubey et al. (1974), deposited in U.S. National Museum Helminthological Collection, USDA, Beltsville, Maryland as USNM Helm. Coll. no. 18450; paratypes from a horse from Cornell University from which the organism was cultured in vitro were deposited as USNM Helm. Coll. no. 18451.

Etymology: The species name is derived from neural (Greek) and refers to the location of the parasite.

\section{Remarks}

Structurally, schizonts of $S$. neurona closely resemble the schizonts of other species of Sarcocystis and Frenkelia (Krampitz et al. 1976; Göbel et al., 1978; Geisel et al. 1979; Dubey, Speer, and Fayer, 1989). Also the merozoites of $S$. neurona lack rhoptries, are located free in the host cell cytoplasm and divide by endopolygeny. The absence of rhoptries in merozoites distinguishes $S$. neurona, other species of Sarcocystis and Frenkelia from any other cyst-forming coccidian parasite found in domestic animals. The absence of rhoptries in $S$. neurona was mentioned also by Simpson and Mayhew (1980). Although Cusick et al. (1974) did not specifically mention the absence of rhoptries, none is visible in their excellent illustrations.

Sarcocystis neurona is distinct structurally and antigenically from $T$. gondii and $N$. canicum. Toxoplasma gondii and $N$. caninum divide into 2 zoites by endodyogeny, whereas $S$. neurona divides simultaneously into several organisms by endopolygeny. Sarcocystis neurona did not react with sera against $T$. gondii, H. hammondi, C. bigenetica, and N. caninum, but reacted positively with $S$. cruzi antiserum. Both schizonts and sarcocysts of cattle, sheep, and goat Sarcocystis spp. (S. cruzi, S. tenella, S. capracanis) reacted with the $S$. cruzi antiserum. The intensity of reaction in $S$. neurona was of the same magnitude as that in control Sarcocystis spp. slides.

The positive reactivity of $S$. neurona with $S$. cruzi antiserum indicates its close relationship with other species of Sarcocystis. Antigenic relationship presently cannot be used to differentiate species within the genus Sarcocystis because all Sarcocystis species tested up to now cross-react serologically with each other (Dubey, Speer, and Fayer, 1989). Although $S$. neurona most closely resembles Sarcocystis species and Frenkelia, it differs in structure and location from any of the known species of Sarcocystis in livestock (Dubey, Speer, and Fayer, 1989). The schizonts of $S$. neurona generally were not seen in endothelium of horses, were located exclusively in the brain and spinal cord, and contained a prominent residual body. Schizonts of all other known species of Sarcocystis in livestock, including the tra- 


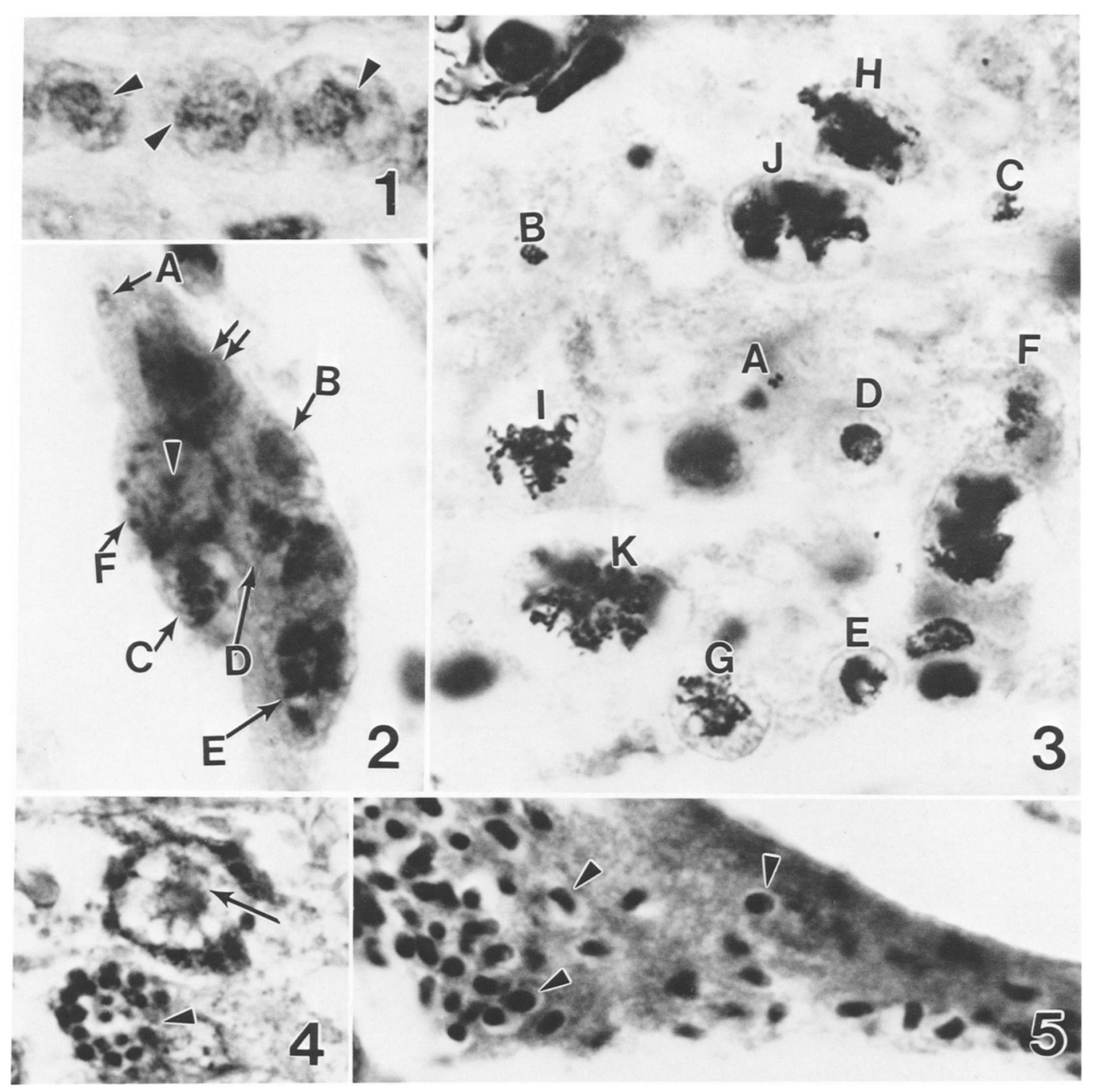

FIGURES 1-5. Stages of Sarcocystis neurona n. sp. in the spinal cord of naturally infected horses. Figures 1, 3-5 are from 1 horse. All $\times 1,500$. 1. Three uninucleated schizonts with differentiating nuclei (arrowheads). Periodic acid Schiff hematoxylin stain. 2. Multiple schizonts in a neuron. A, merozoite with central nucleus; B, schizonts with undifferentiated nuclei; $\mathrm{C}$, schizont with a single nucleus with a prominent nucleolus; D, E, schizonts with multilobed nucleus; $F$, mature schizont with merozoites around a central residual body (arrowhead). Double arrows point to the host cell nucleus. Periodic acid Schiff hematoxylin stain. 3. Eleven (A-K) schizonts in presumed order of nuclear differentiation. A, merozoite with a small nucleus; K, schizont with a highly lobulated nucleus. The schizont boundaries are clear in G, H, and J. Only nuclei are stained. Wilder's ammoniacal silver stain. 4. Two schizonts. The top schizont has a residual body (arrow). The merozoites are cut in cross section (arrowhead) in the bottom schizont. Hematoxylin and eosin stain. 5. Numerous individual merozoites (arrowheads) in a neuron. Hematoxylin and eosin stain.

ditional Sarcocystis species of the horse (Sarcocystis fayeri), are located in blood vessels throughout the body and do not have a residual body, at least under the light microscope (Fayer and Dubey, 1982; Dubey, Speer, and Fayer, 1989). None of the other species of Sarcocystis causes the type of encephalomyelitis seen in EPM. Furthermore, none of the horses and ponies inoculated with 10 species of Sarcocystis (including $S$. fayeri and $S$. cruzi, T. gondii, H. hammondi, and Car- yospora sp.) developed EPM-like disease (Fayer and Dubey, 1987).

Organisms similar to $S$. neurona also are associated with encephalomyelitis in sheep, raccoons, and dogs, but infections are rare and, therefore, it has been difficult to study their life cycles (Dubey, Speer, and Fayer, 1989; Dubey, Speer, Munday, and Lipscomb, 1989; Dubey, Hamir et al., 1990; Dubey and Slife, 1990; Dubey et al., 1991). The organisms causing encepha- 


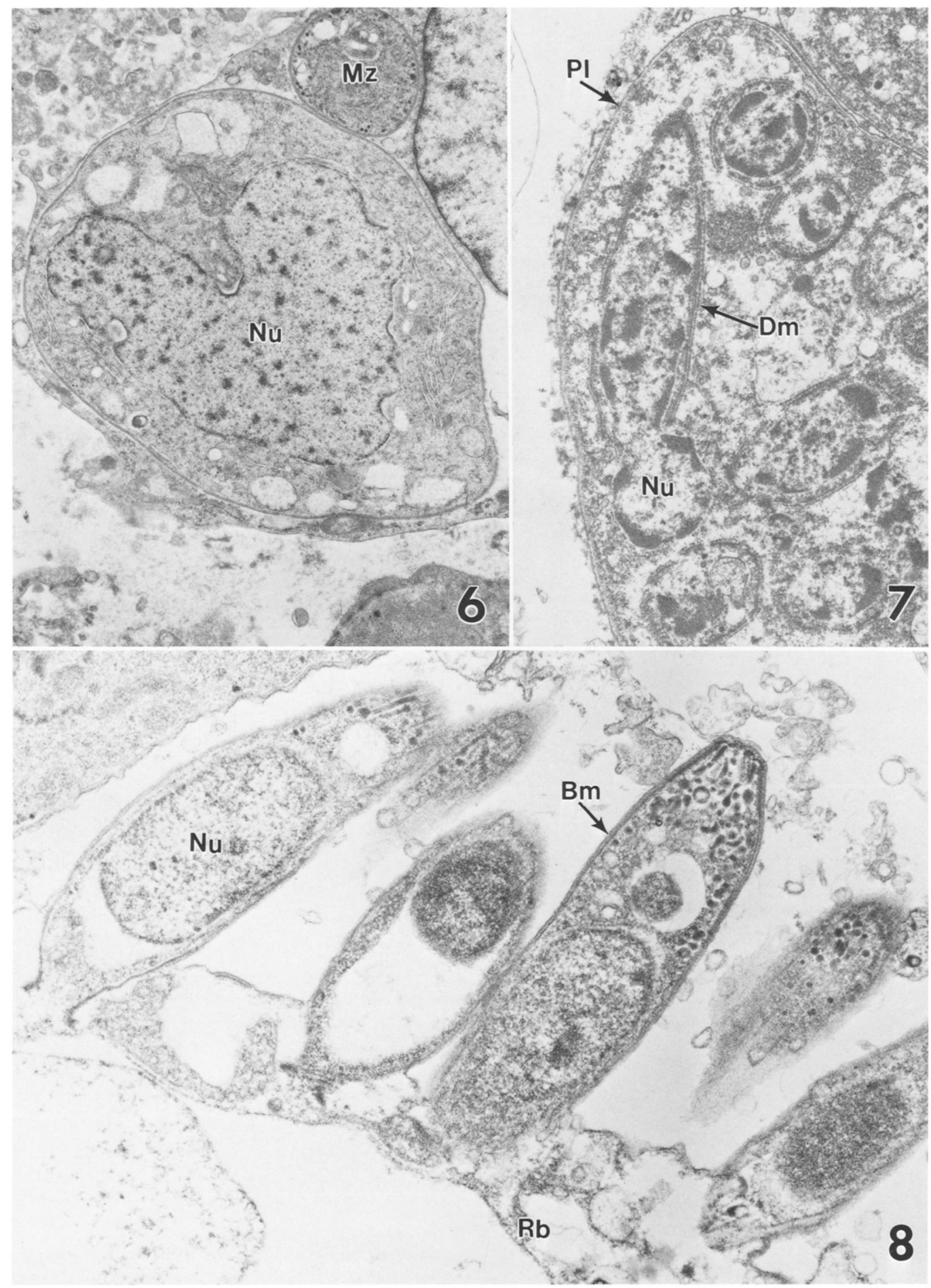

FIGURES 6-8. Transmission electron micrographs of Sarcocystis neurona n. sp. in cells of the horse (Figs. 6, 7) and cultured bovine monocytes (Fig. 8). 6. Spheroidal schizont and merozoite (Mz); Nu, nucleus of schizont. $\times 7,500$. 7. Schizont in intermediate stage of merozoite formation; Dm, developing merozoite; Nu, nucleus of developing merozoite; $\mathrm{Pl}$, plasmalemma of schizont. $\times 11,000.8$. Merozoites in final stages of budding from the residual body $(\mathrm{Rb})$; $\mathrm{BM}$, budding merozoites; $\mathrm{Nu}$, nucleus. $\times 12,000$. 


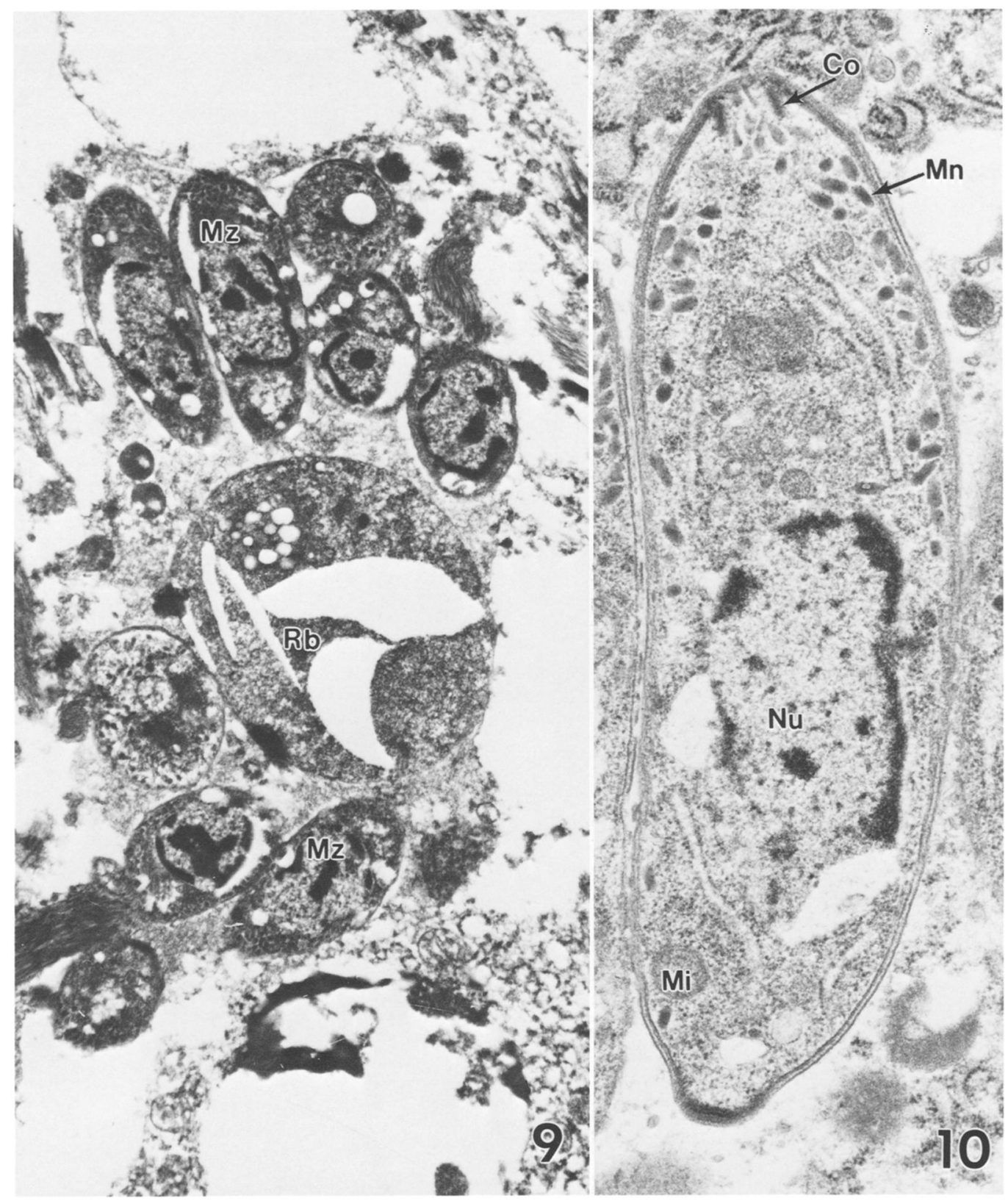

Figures 9, 10. Transmission electron micrographs of Sarcocystis neurona n. sp. in cells of the horse. 9. Mature schizont showing 8 merozoites $(\mathrm{Mz})$ and a large residual body $(\mathrm{Rb}) . \times 9,980.10$. Merozoite. Co, conoid; $\mathrm{Mi}$, mitochondrion; $\mathrm{Mn}$, microneme; $\mathrm{Nu}$, nucleus. $\times 24,900$.

lomyelitis in sheep and raccoons are similar structurally to $S$. neurona and they are, like $S$. neurona, restricted to the brain and spinal cord. However, the organism in the dog also causes infections in extraneural organs.

The type of host cells most commonly parasitized by $S$. neurona varied a great deal. Although up to 10 organisms were seen in the cytoplasm of macrophages and rarely in neutrophils, it could not be determined whether the organisms divided in these cells or merely were engulfed. In one horse, as many as 14 schizonts in different stages of development were seen within a single neuron. There were as many as 120 individual merozoites in a single neuron. Both immature and ma- 
ture schizonts were seen extracellularly in necrotic areas of brain and spinal cord. Schizonts occasionally were seen in multinucleated giant cells.

\section{DISCUSSION}

The organism cultured in bovine monocytes was similar structurally to $S$. neurona in fixed tissues of naturally infected horses. The final identity of the cultured organism will have to be confirmed with further study. The morphologic description of $S$. neurona from naturally infected horses provided in this report should serve as a basis to compare the results of further research with the cultured organism.

The genus Frenkelia is very similar to the genus Sarcocystis. The genus Frenkelia was proposed by Biocca (1968) for the lobulated cysts found in the brain of rodents before the discovery of the life cycles of Sarcocystis and Frenkelia. Both Sarcocystis and Frenkelia are similar structurally and have a similar 2-host predator-prey life cycle. The sexual phase of their cycle is restricted to the intestine of the definitive (predator) host and the asexual phase is in the intermediate (prey) hosts. Because of this close similarity, it has been suggested that Frenkelia should be synonymized with Sarcocystis. However, the host range for Frenkelia is restricted. Only predatory birds (buzzard, hawk) have been found as definitive hosts for Frenkelia; whereas, many mammals, birds, and reptiles act as definitive hosts for Sarcocystis species (Dubey, Speer, and Fayer, 1989). Frenkelia schizonts have been found only in the liver and tissue cysts only in the central nervous system of rodents; whereas, Sarcocystis schizonts may be found throughout the body, and sarcocysts typically occur in striated muscles. Therefore, Dubey, Speer, and Fayer (1989) recommended retaining the genus Frenkelia.

\section{ACKNOWLEDGMENTS}

We thank Drs. I. G. Mayhew, R. B. Higgins, D. A. Stoffregen, P. Rowland, K. S. Todd, S. W. Weisbrode, R. C. Giles, Stauffer Miller, and numerous other scientists for submitting histological sections from affected horses; Dr. R. Fayer for advice; Drs. D. S. Lindsay and C. A. Sundermann for the Caryospora antiserum; and Eva Kovacs, J. A. Blixt, Debra Conner, and Charlie Brown for technical assistance. This study was funded in part by the Harry M. Zweig Memorial Fund for equine research and the Montana State University Agricultural Experiment Station
(MSUAES), Bozeman, Montana. MSUAES Journal Series No. J2545.

\section{LITERATURE CITED}

BEECH, J. 1974. Equine protozoan encephalomyelitis. Veterinary Medicine/Small Animal Clinician 69: 1562-1566.

, AND D. C. DodD. 1974. Toxoplasma-like encephalitis in the horse. Veterinary Pathology 11: 87-96.

BioccA, E. 1968. Class Toxoplasmatea, critical review and proposal of the new name Frenkelia gen. $\mathrm{n}$. for M-organism. Parassitologia 10: 89-98.

Boy, M. G., D. T. Galligan, AND T. J. Divers. 1990. Protozoal encephalomyelitis in horses: 82 cases (1972-1986). Journal of the American Veterinary Medical Association 196: 632-634.

BReWER, B. D., AND I. G. MAYHEW. 1988. Multifocal neurologic disease in a horse. Equine Veterinary Science 8: 302-304.

Brown, T. T., AND C. S. Patton. 1977. Protozoan encephalomyelitis in horses. Journal of the American Veterinary Medical Association 171: 492.

Clark, E. G., H. G. G. Townsend, and N. T. MCKENZIE. 1981. Equine protozoal myeloencephalitis: A report of two cases from western Canada. Canadian Veterinary Journal 22: 140-144.

Cusick, P. K., D. M. Sells, D. P. Hamilton, and H. J. HARDENBROOK. 1974. Toxoplasmosis in two horses. Journal of the American Veterinary Medical Association 164: 77-80.

DorR, T. E., R. J. Higgins, C. A. DANgler, J. E. Madigan, ANd C. L. Witham. 1984. Protozoal myeloencephalitis in horses in California. Journal of the American Veterinary Medical Association 185: 801-802.

DubeY, J. P. 1974. Toxoplasmosis in horses. Journal of the American Veterinary Medical Association 165: 668 .

1982. Development of ox-coyote cycle of Sarcocystis cruzi. Journal of Protozoology 29: 591601.

, S. S. Black, L. T. Sangster, D. S. Lindsay, C. A. Sunderman, ANd M. J. Topper. 1990. Caryospora-associated dermatitis in dogs. Journal of Parasitology 76: 552-556.

- G. W. Davis, A. Koestner, and K. Kiryu. 1974. Equine encephalomyelitis due to a protozoan parasite resembling Toxoplasma gondii. Journal of the American Veterinary Medical Association 165: 249-255.

- , A. N. Hamir, C. A. Hanlon, M. J. Topper, AND C. E. RuPPRECHT. 1990. Fatal necrotizing encephalitis in a raccoon associated with a Sarcocystis-like protozoon. Journal of Veterinary Diagnostic Investigation 2: 345-347.

- , AND S. Miller. 1986. Equine protozoal myeloencephalitis in a pony. Journal of the American Veterinary Medical Association 188: 1311-1312.

- AND L. N. SLIFE. 1990. Fatal encephalitis in a dog associated with an unidentified coccidian parasite. Journal of Veterinary Diagnostic Investigation 2: 233-236. 
J. TOPPER. 1991. Fatal cutaneous and visceral infection in a Rottweiler dog associated with a Sarcocystis-like protozoon. Journal of Veterinary Diagnostic Investigation 3: 72-75.

, C. A. Speer, C. A. Callis, and J. A. Blixt. 1982. Development of sheep-canid cycle of Sarcocystis tenella. Canadian Journal of Zoology 60: 2464-2477.

, G. P. Epling, AND J. A. BLIXT. 1984 Sarcocystis capracanis: Development in goats, dogs and coyotes. International Goat Sheep Research 2: 252-265.

- AND R. FAYER. 1989. Sarcocystosis of animals and man. CRC Press, Boca Raton, Florida, $215 \mathrm{p}$.

, B. L. MUNDAY, AND T. P. LIPSCOMB, 1989. Ovine sporozoan encephalomyelitis linked to Sarcocystis infection. Veterinary Parasitology 34: 159-163.

FAYER, R., AND J. P. DuBEy. 1982. Development of Sarcocystis fayeri in the equine. Journal of Parasitology 68: 856-860.

, AND —. 1987. Comparative epidemiology of coccidia: Clues to the etiology of equine protozoal myeloencephalitis. International Journal for Parasitology 17: 615-620.

, I. G. Mayhew, J. D. Baird, S. G. Dill, J. H. Foreman, J. C. Cox, R. J. Higgins, S. M. Reed, W. W. Ruoff, R. W. SweEney, AND P. Tuttle. 1990. Epidemiology of equine protozoal myeloencephalitis in North America based on histologically confirmed cases. A report. Journal of Veterinary Internal Medicine 4: 54-57.

Geisel, O., E. Kaiser, O. Vogel, H. E. Krampitz, AND M. ROMMEL. 1979. Pathomorphologic findings in short-tailed voles (Microtus agrestis) experimentally-infected with Frenkelia microti. Journal of Wildlife Diseases 15: 267-270.

GÖBEL, E., M. ROMMEL, AND H. E. KRAMPITZ. 1978. Ultrastrukturelle Untersuchungen zur ungeschlechtlichen Vermehrung von Frenkelia in der Leber der Rötelmaus. Zeitschrift für Parasitenkunde 55: $29-42$.
Granstrom, D. E., R. K. Ridley, Y. BaOAN, AND L. J. GERSHWIN. 1990. Immunodominant proteins of Sarcocystis cruzi bradyzoites isolated from cattle affected or nonaffected with eosinophilic myositis. American Journal of Veterinary Research 51: 1151-1155.

Krampitz, H. E., M. Rommel, O. Geisel, aNd E. KaISER. 1976. Beiträge zum Lebenszyklus der Frenkelien. II. Die ungeschlechtliche Entwicklung von Frenkelia clethrionomyobuteonis in der Rötelmaus. Zeitschrift für Parasitenkunde 51: 7-14.

Lindsay, D. S., AND J. P. DubeY. 1989. Immunohistochemical diagnosis of Neospora caninum in tissue sections. American Journal of Veterinary Research 50: 1981-1983.

Madigan, J. F., AND R. J. Higgins. 1987. Equine protozoal myeloencephalitis. Veterinary Clinics of North America: Equine Practice 3: 397-402.

Mayhew, I. G., AND A. DE LahunTA. 1978. Neuropathology. In Spinal cord disease in the horse, I. G. Mayhew, A. de Lahunta, R. H. Whitlock, L. Krook, and J. B. Tusker (eds.). The Cornell Veterinarian 68: 106-147.

, R. W. Dellers, J. F. Timoney, M. J. Kemen, R. FAYER, AND M. N. LUNDE. 1978. Microbiology and serology. In Spinal cord disease in the horse, I. G. Mayhew, A. de Lahunta, R. H. Whitlock, L. Krook, and J. B. Tusker (eds.). The Cornell Veterinarian 68: 148-160.

, AND E. C. Greiner. 1986. Protozoal diseases. Equine protozoal myeloencephalitis. Veterinary Clinics of North America: Equine Practice 2: 439459.

Simpson, C. F., AND I. G. MAYHEw. 1980. Evidence for Sarcocystis as the etiologic agent of equine protozoal myeloencephalitis. Journal of Protozoology 27: 288-292.

Speer, C. A., D. W. Reduker, D. E. Burgess, W. M. Whitmire, AND G. A. Splitter. 1985. Lymphokine-induced inhibition of growth of Eimeria bovis and Eimeria papillata (Apicomplexa) in cultured bovine monocytes. Infection and Immunity 50: $566-571$. 